\title{
Incidence of incidental cancer in transurethral resection of prostate specimens: a 10-year retrospective analysis
}

Döndü Nergiz ${ }^{*}$, Hülya Tosun Yıldırım and Şenay Yıldırım

\begin{abstract}
Background: Prostate cancer can be detected incidentally in patients undergoing transurethral resection of the prostate for benign prostatic hyperplasia. Therefore, it is very important that the transurethral resection of the prostate specimen is evaluated carefully for accurate grading and staging. The aim of this study was to investigate the frequency of incidental prostate cancer and its relationship with clinicopathological findings.

Methods: The study included a total of 900 patients, who underwent transurethral resection of the prostate for benign prostatic hyperplasia treatment between June 2010 and June 2020. Patient age, prostate-specific antigen (PSA) levels and resected prostate weight were assessed, and the tumor stage, Gleason grade group, lymphovascular and perineural invasion status were also evaluated in the incidental prostate cancer group. The association between these parameters and prostate cancer detection was analyzed.

Results: Incidental detection of prostate cancer was determined at the rate of 13.3\%. The incidental prostate cancer group had a significantly higher mean age and PSA levels compared to the benign prostatic hyperplasia group. The weight of the resected specimen had no impact on the incidence of incidental prostate cancer. Of the total 120 incidental prostate cancer cases, 59 (49.2\%) were stage T1a and 61 (50.8\%) were stage T1b. No significant difference was determined between the T1 stages and age distribution, but a statistically significant difference was determined in the other clinicopathological parameters.

Conclusions: The results of this study demonstrated that the incidence of incidental prostate cancer detection was related to age and PSA levels and increased, especially in those aged $\geq 60$ years and/or PSA level $\geq 4 \mathrm{ng} / \mathrm{mL}$. To avoid overlooking incidental prostate cancer in these patients, it can be recommended that material is sufficiently sampled and carefully evaluated, and when necessary, all resected specimens are examined. Although no significant correlation was determined between specimen weight and the incidence of incidental prostate cancer, as a significant difference was determined in T1 stages, this suggests that the amount of material evaluated could change the sub-stage.
\end{abstract}

Keywords: Benign prostatic hyperplasia, Incidental prostate cancer, Prostate-specific antigen, Transurethral resection

*Correspondence: drdnergiz@gmail.com

Department of Pathology, University of Health Sciences, Antalya Training and Research Hospital, Kazım Karabekir Street, 07050 Muratpaşa, Antalya, Turkey

\section{Background}

At a frequency of $13.5 \%$, prostate cancer is the second most common cancer in men and is one of the most important causes of morbidity and responsible for $6.7 \%$ of cancer-related mortality, worldwide. The serum prostate-specific antigen (PSA) screening of asymptomatic patients and determination of latent tumors in autopsies 
are thought to have had a great effect on the increasing incidence in recent years [1].

Transurethral resection of the prostate (TUR-P) is considered the standard method of surgical treatment for benign prostatic hyperplasia (BPH) [2]. TUR-P targets the transitional zone of the prostate. The majority of prostate cancers arise in the peripheral zones, and transrectal needle core biopsy is the gold standard for confirming the diagnosis in patients with elevated levels of PSA. Prostate cancer isolated exclusively in the transitional zone is uncommon, and a minority of tumors may not cause a rise in PSA, especially those of low volume $[3,4]$. Several recent studies have reported that cancers arising from the transitional zone have a more favorable prognosis than tumors that originate in the peripheral zone $[4,5]$.

Clinical T1 or incidental prostate cancer (IPC) is defined as prostate cancer that is not evident clinically by direct rectal examination or imaging modalities and is diagnosed at the time of TUR-P for benign prostatic disease [6, 7]. The incidence of IPC in TUR-P specimens has greatly decreased due to the widespread use of serum PSA screening. In various studies in the literature, the prevalence of IPC is reported to vary between 1.4 and $16.7 \%$ [5].

Most IPCs are considered clinically insignificant, but recent studies have suggested that in some the clinical course becomes more unfavorable [8]. Some IPCs have been shown to be clinically relevant, specifically tumors with a higher Gleason score and stage T1b [6]. The hypothesis of this study was that a more comprehensive clinicopathological assessment of incidental prostate cancer in TUR-P specimens would reveal important associations in this cancer and may aid treatment decisions.

In this study, the incidence of IPC was investigated in patients who underwent TUR-P for BPH and comparisons were made of age, resected specimen weight and PSA level between BPH and IPC groups. It was also aimed to investigate associations between $\mathrm{T} 1$ stages and age, specimen weight, PSA level, Gleason grade group (GG), perineural invasion (PNI) and lymphovascular invasion (LVI) in patients with IPC.

\section{Methods}

\subsection{Patient selection}

The study group was retrospectively selected from 900 patients who underwent TUR-P for BPH treatment between June 2010 and June 2020. Patients with no suspicion of malignancy with direct rectal examination and imaging techniques were included in the study. The medical history of all patients who met the inclusion criteria was reviewed, and any patients with known atypical small acinar proliferation, high-grade prostatic intraepithelial neoplasia and prostate cancer were excluded from the study. Patients were also excluded if they had been diagnosed with high-grade prostatic intraepithelial neoplasia on TUR-P.

Demographic data, preoperative serum total PSA levels and imaging findings of the cases were retrieved from the hospital medical records and patient files. Histopathological findings were obtained from the pathology reports. The tissue slides in the pathology archive and/or the sections obtained from the paraffin blocks were re-evaluated in patients where the pathology reports did not include sufficient data. Consecutive sections were taken from the paraffin blocks of patients with suspected benign and malignant mimickers. To evaluate the suspicious foci in some patients, immunohistochemical stains of p63 (Ventana, anti-p63 (4A4) mouse monoclonal primary antibody), HMWCK (Ventana, anti-keratin (34ßE12) mouse monoclonal primary antibody) and/or AMACR (Ventana, anti-p504s (SP116) rabbit monoclonal primary antibody) were used (Fig. 1).

\subsection{Specimen handling and evaluation}

All the TUR-P specimens were weighed. The method recommended in The College of American Pathologists guidelines was used for the sampling of specimens. TUR-P specimens weighing $\leq 12 \mathrm{~g}$ were submitted in entirety, usually in 6-8 cassettes. For specimens weighing $>12 \mathrm{~g}$, the initial $12 \mathrm{~g}$ was submitted and 1 cassette was submitted for every additional $5 \mathrm{~g}$ of remaining tissue $[9,10]$. In addition, in patients with IPC, resampling was performed and all remaining tissue was submitted for histopathological evaluation.

The percentage of tumor involvement was used to determine the clinical $\mathrm{T} 1$ sub-stage, with $\leq 5 \%$ involvement indicating T1a and $>5 \% \mathrm{~T} 1 \mathrm{~b}[9,10]$.

Patient age, resected specimen weight and preoperative serum total PSA level of the patients were assessed. In the IPC group, tumor stage, Gleason GG, LVI and PNI status were evaluated. Each group was further subdivided into categories based on age, PSA levels and specimen weight (age categories: $\leq 59,60-69,70-79, \geq 80$ years; PSA categories: $0.00-0.99,1.00-2.49,2.50-3.99,4.00-$ 9.99, $\geq 10.00 \mathrm{ng} / \mathrm{mL}$; and TUR-P specimen weight categories: $\leq 10 \mathrm{~g}$ and $>10 \mathrm{~g}$ ). The International Society of Urological Pathology consensus guidelines were used for Gleason group scoring [11].

\subsection{Ethics approval and consent to participate}

This study was reviewed and approved by the Ethics Committee of University of Health Sciences, Antalya Training and Research Hospital (approval number: 10/11, dated: $3 / 7 / 2020$ ). Consent to participate was not applicable as this was a retrospective study. This decision to 


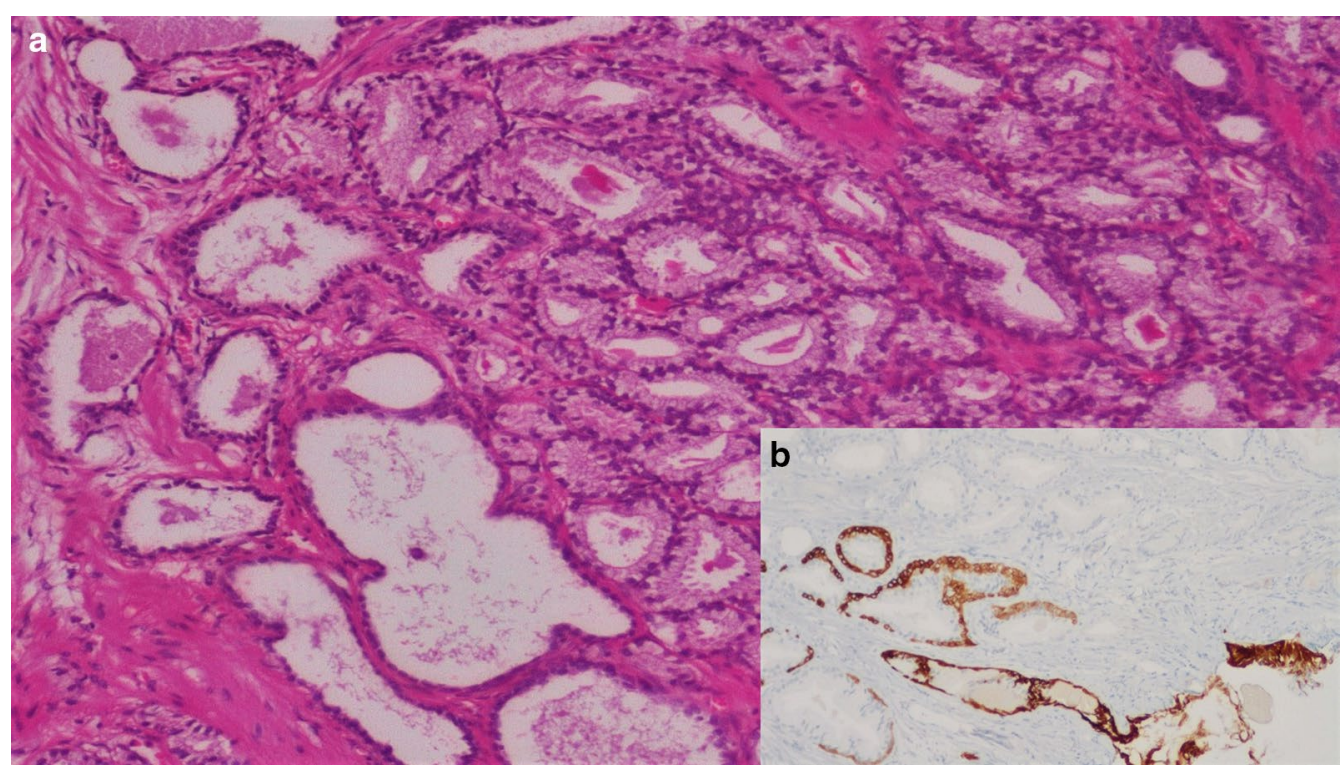

Fig. 1 a Focus of incidental prostate cancer-well-formed, small to medium sized infiltrative glands (hematoxylin and eosin, $\times 100$ ), $\mathbf{b}$ Loss of HMWCK expression in prostate cancer focus (immunohistochemistry, $\times 100$ )

waiver was approved by the Ethics Committee of University of Health Sciences, Antalya Training and Research Hospital (approval number: 10/11, dated: 3/7/2020). The research followed the tenets of the Declaration of Helsinki.

\subsection{Statistical analysis}

Data obtained in the study were analyzed statistically using SPSS 18.0 (Statistical Package for Social Sciences Inc., Chicago, IL, USA) and Epi Info Epidemiological 7 Statcalc software.

Data were presented with descriptive statistics, as number ( $\mathrm{n}$ ) and percentage (\%) and mean \pm standard deviation (SD) and mean (min-max) values. Causal relationships were analyzed with a $95 \%$ confidence interval (CI) and a margin of error of 5\%. The Pearson Chi-square test, Yates Corrected Chi-square test and Fisher's exact test were used to analyze the relationships between categorical data in independent groups. The Student's $t$ test was used to analyze the continuous data determined by measurement of two independent groups. A value of $p<0.05$ was considered statistically significant in all tests.

\section{Results}

The study included 900 patients. Prostate cancer was determined incidentally in 120 of 900 (13.3\%) patients. $\mathrm{BPH}$ was observed in the remaining 780 cases. Chronic prostatitis was detected in 280 (35.9\%) of $780 \mathrm{BPH}$ cases, and 38 (4.9\%) of these 280 cases had activity findings.

The incidental prostate cancer group had significantly higher mean age and PSA levels compared to the $\mathrm{BPH}$ group $(p<0.001, p=0.036$, respectively) (Table 1$)$. The frequency of IPC detection increased, especially in patients aged $\geq 60$ years and with PSA level $\geq 4.00 \mathrm{ng} /$ $\mathrm{mL}$ (Table 2). When the mean specimen weights were compared and the specimen weight cut-off point was taken as $10 \mathrm{~g}$, no statistically significant difference was determined between the IPC and BPH groups $(p=0.13$, $p=0.15$, respectively) (Table 3 ).

Table 1 Patient characteristics in the incidental prostate cancer and benign prostatic hyperplasia groups

\begin{tabular}{lllll}
\hline Variables & $\begin{array}{l}\text { IPC group }(\boldsymbol{n}: \mathbf{1 2 0}) \\
\text { Mean } \pm \text { SD (range) }\end{array}$ & $\begin{array}{l}\text { BPH group }(\boldsymbol{n}: \mathbf{7 8 0}) \\
\text { Mean } \pm \text { SD (range) }\end{array}$ & $\begin{array}{l}\text { Total }(\boldsymbol{n}: \mathbf{9 0 0}) \\
\text { Mean } \pm \text { SD (range) }\end{array}$ \\
\hline Age (years) & $72.35 \pm 8.56(54-94)$ & $68.24 \pm 8.57(24-94)$ & $68.79 \pm 8.68(24-94)$ & $\boldsymbol{p}$ \\
PSA (ng/mL) & $4.90 \pm 6.36(0.01-44.50)$ & $3.62 \pm 4.85(0.12-49.60)$ & $3.79 \pm 5.10(0.01-49.60)$ \\
Specimen weight (g) & $16.13 \pm 11.59(1.5-60)$ & $18.06 \pm 13.33(1-100)$ & $17.80 \pm 13.12(1-100)$ & 0.036 \\
\hline
\end{tabular}

IPC incidental prostate cancer, $B P H$ benign prostatic hyperplasia, PSA prostate-specific antigen, SD standard deviation

Bold values indicate statistical significance at the $p<0.05$ level 
Table 2 Comparison of age and PSA levels in the incidental prostate cancer and benign prostatic hyperplasia groups

\begin{tabular}{lcccc}
\hline Variables & $\begin{array}{l}\text { IPC group } \\
\mathbf{n}(\%)\end{array}$ & $\begin{array}{l}\text { BPH group } \\
\mathbf{n}(\%)\end{array}$ & $\begin{array}{l}\text { Total } \\
\mathbf{n}(\%)\end{array}$ & $\boldsymbol{p}$ \\
\hline Age (years) & & & & $\mathbf{0 . 0 0 0 1}$ \\
$\leq 59$ & $7(5.4 \%)$ & $122(94.6 \%)$ & $129(14.3 \%)$ & \\
$60-69$ & $44(12.4 \%)$ & $312(87.6 \%)$ & $356(39.6 \%)$ & \\
$70-79$ & $45(14.1 \%)$ & $274(85.9 \%)$ & $319(35.4 \%)$ & \\
$\geq 80$ & $24(25.0 \%)$ & $72(75.0 \%)$ & $96(10.7 \%)$ & \\
PSA (ng/mL) & & & & $\mathbf{0 . 0 1 9}$ \\
$0.00-0.99$ & $16(8.1 \%)$ & $182(91.9 \%)$ & $198(22.0 \%)$ & \\
$1.00-2.49$ & $43(15.1 \%)$ & $241(84.9 \%)$ & $284(31.6 \%)$ & \\
$2.50-3.99$ & $15(10.8 \%)$ & $124(89.2 \%)$ & $139(15.4 \%)$ & \\
$4.00-9.99$ & $32(14.6 \%)$ & $187(85.4 \%)$ & $219(24.3 \%)$ & \\
$\geq 10.00$ & $14(23.3 \%)$ & $46(76.7 \%)$ & $60(6.7 \%)$ & \\
Total & $120(13.3 \%)$ & $780(86.7 \%)$ & $900(100.0 \%)$ & \\
\hline
\end{tabular}

$I P C$ incidental prostate cancer, $B P H$ benign prostatic hyperplasia, $P S A$ prostatespecific antigen

Bold values indicate statistical significance at the $p<0.05$ level

Of the total 120 IPC cases, $59(49.2 \%)$ patients were stage $\mathrm{T} 1 \mathrm{a}$ and $61(50.8 \%)$ were stage $\mathrm{T} 1 \mathrm{~b}$. The mean age of the T1b stage patients was significantly older than those at T1a stage $(p=0.048)$ (Table 4$)$, but the difference in age distribution between T1a and T1b stages was not statistically significant $(p=0.087)$ (Table 5$)$. T1b stage was detected more frequently at PSA levels of $\geq 4.00 \mathrm{ng} /$ $\mathrm{mL}$ compared to other PSA levels. There was a statistically significant difference in PSA level distribution between T1a and T1b stages $(p=0.041)$. Gleason GG 1 was found at a significantly higher rate in patients with T1a stage than in T1b. Gleason GG 4-5 was detected more frequently in patients with T1b stage $(p<0.001)$. PNI and LVI status was statistically significantly different between the T1a and T1b groups $(p<0.001, p<0.001$, respectively) (Table 5).

The mean weight of the resected specimens was significantly lower in T1b stage than T1a stage $(p=0.017)$ (Table 4). A statistically significant difference was determined between stage T1a and T1b tumors, with TUR-P weight of $10 \mathrm{~g}$ taken as the cut-off point. The possibility of T1a detection increased 2.51-fold (95\% CI range 1.195.31, $p=0.024)$ in those with specimen weight $>10 \mathrm{~g}$ compared to those $\leq 10 \mathrm{~g}$ (Table 6).

\section{Discussion}

TUR-P operation is the most common method applied in the treatment of $\mathrm{BPH}$, and even if rarely, prostate cancer can be detected incidentally. In this study, 900 patients were examined retrospectively to determine the incidence of incidental prostate cancer in patients applied with TUR-P because of $\mathrm{BPH}$ and to evaluate the relationship of age, PSA level and the weight of the resected specimen. A comparison was also made of $\mathrm{T} 1 \mathrm{a}$ and $\mathrm{T} 1 \mathrm{~b}$ stages in IPC patients with various clinicopathological parameters. The results of the study determined the IPC incidence to be $13.3 \%$, and a significant relationship was determined between IPC incidence and age and PSA level. No significant difference was determined between $\mathrm{T}$ stages in respect of age distribution, but a significant

Table 3 Comparison of the specimen weight in the incidental prostate cancer and benign prostatic hyperplasia groups

\begin{tabular}{lllllc}
\hline & $\begin{array}{l}\text { IPC group } \\
\boldsymbol{n}(\%)\end{array}$ & $\begin{array}{l}\text { BPH group } \\
\boldsymbol{n}(\%)\end{array}$ & $\begin{array}{l}\text { Total } \\
\boldsymbol{n}(\%)\end{array}$ & Odds ratio & 95\% Cl range \\
\hline $\begin{array}{l}\text { Specimen weight } \\
(\mathrm{g})\end{array}$ & & & & 0.75 & $0.51-1.12$ \\
$>10$ & $70(58.3 \%)$ & $507(65.0 \%)$ & $577(64.1 \%)$ & 0.156 \\
$\leq 10$ & $50(41.7 \%)$ & $273(35.0 \%)$ & $323(35.9 \%)$ & \\
Total & $120(13.3 \%)$ & $780(86.7 \%)$ & $900(100.0 \%)$ & \\
\hline
\end{tabular}

$I P C$ incidental prostate cancer, $B P H$ benign prostatic hyperplasia, $\mathrm{Cl}$ confidence interval

Table 4 Patient characteristics in T1a and T1b stages

\begin{tabular}{llll}
\hline Variables & $\begin{array}{l}\text { T1a stage }(\boldsymbol{n}: 59) \\
\text { Mean } \pm \text { SD }(\text { range })\end{array}$ & $\begin{array}{l}\text { T1b stage }(\boldsymbol{n}: \mathbf{6 1}) \\
\text { Mean } \pm \text { SD }(\text { range })\end{array}$ & $\begin{array}{l}\text { Total }(\boldsymbol{n}: \mathbf{1 2 0}) \\
\text { Mean } \pm \text { SD (range) }\end{array}$ \\
\hline Age (years) & $70.78 \pm 8.01(56-92)$ & $73.87 \pm 8.87(54-94)$ & $72.35 \pm 8.56(54-94)$ \\
PSA (ng/mL) & $3.28 \pm 3.29(0.01-18.72)$ & $6.47 \pm 8.04(0.07-44.50)$ & $4.90 \pm 6.36(0.01-44.50)$ \\
Specimen weight (g) & $18.70 \pm 13.23(1.5-60)$ & $13.64 \pm 9.18(2-50)$ & $16.13 \pm 11.59(1.5-60)$
\end{tabular}

PSA prostate-specific antigen, SD standard deviation

Bold values indicate statistical significance at the $p<0.05$ level 
Table 5 Comparison of different variables in T1a and T1b stages

\begin{tabular}{|c|c|c|c|c|}
\hline Variables & $\begin{array}{l}\text { T1a stage } \\
\text { n (\%) }\end{array}$ & $\begin{array}{l}\text { T1b stage } \\
\text { n (\%) }\end{array}$ & $\begin{array}{l}\text { Total } \\
\text { n (\%) }\end{array}$ & $p$ \\
\hline Age (years) & & & & 0.087 \\
\hline$\leq 59$ & $3(42.9 \%)$ & $4(57.1 \%)$ & $7(5.8 \%)$ & \\
\hline $60-69$ & $27(61.4 \%)$ & $17(38.6 \%)$ & $44(36.7 \%)$ & \\
\hline 70-79 & $22(48.9 \%)$ & $23(51.1 \%)$ & $45(37.5)$ & \\
\hline$\geq 80$ & $7(29.2 \%)$ & $17(70.8 \%)$ & $24(20.0 \%)$ & \\
\hline PSA (ng/mL) & & & & 0.041 \\
\hline $0.00-0.99$ & $8(50.0 \%)$ & $8(50.0 \%)$ & $16(13.3 \%)$ & \\
\hline $1.00-2.49$ & $27(62.8 \%)$ & $16(37.2 \%)$ & $43(35.8 \%)$ & \\
\hline $2.50-3.99$ & $9(60.0 \%)$ & $6(40.0 \%)$ & $15(12.5 \%)$ & \\
\hline $4.00-9.99$ & $12(37.5 \%)$ & $20(62.5 \%)$ & $32(26.7 \%)$ & \\
\hline$\geq 10.00$ & $3(21.4 \%)$ & $11(78.6 \%)$ & $14(11.7 \%)$ & \\
\hline Gleason grade group & & & & 0.0001 \\
\hline Group 1 & $49(73.1 \%)$ & $18(26.9 \%)$ & $67(55.8 \%)$ & \\
\hline Group 2 & $5(50.0 \%)$ & $5(50.0 \%)$ & $10(8.3 \%)$ & \\
\hline Group 3 & $2(40.0 \%)$ & $3(60.0 \%)$ & $5(4.2 \%)$ & \\
\hline Group 4 & $1(7.1 \%)$ & $13(92.9 \%)$ & $14(11.7 \%)$ & \\
\hline Group 5 & $2(8.3 \%)$ & $22(91.7 \%)$ & $24(20.0 \%)$ & \\
\hline Perineural invasion & & & & 0.0001 \\
\hline Positive & $1(4.4 \%)$ & $22(95.6 \%)$ & $23(19.2 \%)$ & \\
\hline Negative & $58(59.8 \%)$ & $39(40.2 \%)$ & $97(80.8 \%)$ & \\
\hline $\begin{array}{l}\text { Lymphovascular inva- } \\
\text { sion }\end{array}$ & & & & 0.0001 \\
\hline Positive & $0(0.0 \%)$ & $9(100.0 \%)$ & $9(7.5 \%)$ & \\
\hline Negative & $59(53.2 \%)$ & $52(46.8 \%)$ & $111(92.5 \%)$ & \\
\hline Total & $59(49.2 \%)$ & $61(50.8 \%)$ & 120 (100.0\%) & \\
\hline
\end{tabular}

PSA prostate-specific antigen

Bold values indicate statistical significance at the $p<0.05$ level

difference was found in respect of other clinicopathological parameters. Prostate cancers of T1a stage were found to be usually Gleason GG 1, and those at T1b stage were Gleason GG 4-5. In the evaluation of the specimen weight, no significant difference was determined between the IPC and BPH groups. In the comparison of $\mathrm{T} 1 \mathrm{a}$ and T1b stages in IPC patients, the mean specimen weight at T1a stage was higher and the frequency of $\mathrm{T} 1 \mathrm{a}$ determination was 2.5 -fold higher in patients with specimen weight $>10 \mathrm{~g}$.

The incidence of prostate cancer has increased in recent years [1]. Serum PSA level, direct rectal examination and imaging modalities can be used for prostate cancer diagnosis, but PSA level is considered a better predictor of cancer than other methods [7]. Serum PSA levels correlate strongly with the risk of prostate cancer, although PSA is not specific to prostate cancer and may be elevated in conditions such as $\mathrm{BPH}$, prostatitis and mechanical manipulation [12]. Although up to $27 \%$ of prostate cancers were determined incidentally before PSA screening, this rate decreased with the start of the widespread use of PSA screening. In several current studies, the prevalence of IPC has been reported to vary between 1.4 and $16.7 \%[5,6]$. The IPC rate in the current study was seen to be consistent with the data reported in the previous literature.

The T1 sub-stages of IPC predict the progression of cancer and disease specific survival [12]. Prostate cancers at T1 stage are a heterogenous group with a high risk of disease progression [3]. In several recent studies, during diagnosis in TUR-P, IPCs have been determined at a higher rate at T1a stage than at T1b stage $[5,6,8,13,14]$. However, there are also studies showing a higher rate at $\mathrm{T} 1 \mathrm{~b}$ stage, or equal rates of T1a and $\mathrm{T} 1 \mathrm{~b}[4,7,15,16]$. In the current study, compared to T1a stage (49.2\%), T1b stage $(50.8 \%)$ was found to be slightly higher.

Sakamoto et al. [8] reported that age and high PSA level were independent risk factors for IPC determination in TUR-P in older patients. A significant difference was determined between IPC and BPH groups in respect of age and mean PSA level in a study by Nafie et al. [15]. Morita et al. [17] also found a significant difference between IPC and BPH groups in respect of mean age, but unlike the study by Nafie et al. [15], there was no significant difference in PSA levels. In the current study, a statistically significant difference was determined between the IPC and BPH groups in respect of mean age and mean PSA level $(p<0.001, p=0.036$, respectively). In addition, the mean age and mean PSA levels in the IPC patients were found to be significantly higher at $\mathrm{T} 1 \mathrm{~b}$

Table 6 Comparison of the specimen weight of patients in the T1a and T1b stages

\begin{tabular}{|c|c|c|c|c|c|c|}
\hline & $\begin{array}{l}\text { T1a stage } \\
n(\%)\end{array}$ & $\begin{array}{l}\text { T1b stage } \\
n(\%)\end{array}$ & $\begin{array}{l}\text { Total } \\
n(\%)\end{array}$ & Odds ratio & $95 \% \mathrm{Cl}$ range & $p$ \\
\hline Specimen weight (g) & & & & 2.51 & $1.19-5.31$ & 0.024 \\
\hline$>10$ & 41 (69.5\%) & $29(47.5 \%)$ & 70 (58.3\%) & & & \\
\hline$\leq 10$ & $18(30.5 \%)$ & $32(52.5 \%)$ & $50(41.7 \%)$ & & & \\
\hline Total & 59 (49.2\%) & $61(50.8 \%)$ & 120 (100.0\%) & & & \\
\hline
\end{tabular}

Cl Confidence interval

Bold values indicate statistical significance at the $p<0.05$ level 
stage ( $p=0.048, p=0.005$, respectively). Argyropoulos et al. [16] compared T1a and T1b stages, and although the difference was not statistically significant, the mean age at T1b stage was found to be higher than at T1a stage, whereas the mean PSA level was slightly higher at T1a stage. In a study by Masue et al. [18], there was reported to be no significant difference in mean age and mean PSA level between T1a and T1b stages.

The current study results of increased IPC incidence in the age group $\geq 60$ years were consistent with the findings in the literature of reports stating maximum IPC incidence in the $\geq 80$ years age group $[17,19]$. In contrast with the findings of the current study, in a study by Silverio et al. [19] which evaluated TUR-P and/or open prostatectomy (OP) specimens, a significant difference was reported in age distribution in the comparison of $\mathrm{T}$ stages, and in every age group, T1a stage was determined at a higher rate than T1b. In a study of TUR-P and OP specimens of patients with PSA values $<4.0 \mathrm{ng} / \mathrm{mL}$ by Masue et al. [18], no statistically significant relationship was found between T1a and T1b stages in respect of age and PSA levels. It was also reported that the peak PSA distribution was $1.00-1.99 \mathrm{ng} / \mathrm{mL}$ in both stage T1a and T1b cases. In the current study, the peak PSA distribution was $1.00-2.49 \mathrm{ng} / \mathrm{mL}$ at T1a stage and $\geq 4.00 \mathrm{ng} / \mathrm{mL}$ at T1b stage $(p=0.041)$.

Morita et al. [17] reported a significant difference in mean specimen weight between the IPC and BPH groups, whereas in the current study, no difference was determined. In addition, in the current study, the specimen weight in IPCs was significantly greater in those at T1a stage compared to $\mathrm{T} 1 \mathrm{~b}(p=0.017)$. In a study by Argyropoulos et al. [16], the mean specimen weight was determined to be higher at T1a stage. The cut-off value used was $20 \mathrm{~g}$ for the resected specimen weight, and IPC was determined at a higher rate in specimens $\leq 20 \mathrm{~g}$ compared to $>20 \mathrm{~g}$. A statistically significant difference was determined between $\mathrm{T} 1 \mathrm{a}$ and $\mathrm{T} 1 \mathrm{~b}$ stages with the $20 \mathrm{~g}$ cut-off value, and all the samples at T1b stage were determined to be $\leq 20 \mathrm{~g}$ compared to $64.7 \%$ at $\mathrm{T} 1 \mathrm{a}$ stage. With a cut-off value of $10 \mathrm{~g}$ used in the current study, no significant difference was determined between the IPC and $\mathrm{BPH}$ groups $(p=0.15)$, but $\mathrm{T} 1 \mathrm{~b}$ stage was determined at a higher rate than $\mathrm{T} 1 \mathrm{a}$ in specimens weighing $\leq 10 \mathrm{~g}(p=0.02)$.

Gleason score is an independent predictor of disease specific survival for TUR-P detected IPC [12]. Argyropoulos et al. [16] reported that $64.7 \%$ of IPCs at T1b stage were Gleason GG 2-5, and all of those at T1a stage were Gleason GG 1. In the study by Silverio et al. [19],
$34.4 \%$ of T1b stage IPCs were Gleason $\mathrm{GG} \geq 2$ and all the T1a stage patients were Gleason GG 1 . In the current study, $44.2 \%$ of the IPCs were Gleason GG $2-5$ as $74.1 \%$ of those at T1b and $26.9 \%$ of those at T1a stage. Gleason GG 1 IPCs were determined at a significantly higher rate at T1a stage than at T1b stage $(p<0.001)$.

Cheng et al. [20] evaluated the lymphovascular invasion status in patients who underwent radical prostatectomy for prostate cancer, and LVI was determined to be an independent risk factor for PSA recurrence and cancer-related death in patients with prostate cancer. In the current study, LVI was found in $14.3 \%$ of the cases at T1b stage and not detected in any of the patients at T1a stage. LVI was determined only in IPC of Gleason GG 4 (33.3\%) and Gleason GG 5 (66.4\%).

It was thought that the inconsistency of the current study results with those of some other studies was due to sample size, inclusion and exclusion criteria, and geographic and racial characteristics.

Various studies have reported that T1b stage IPCs have a worse prognosis than those at T1a stage [13]. The decision "treatment vs no treatment" is judged by life expectancy, tumor characteristic in the pathology report of TUR-P specimen and PSA level following TUR-P [21]. In light of this information, detailed histopathological and clinical evaluations can be considered of great importance to be able to make a correct diagnosis and for the formation of appropriate follow-up and treatment plans. The focus of the current study was to determine the incidence and the risk factors for prostate cancer diagnosed incidentally in TUR-P specimens. In addition, the relationships of T1 stages with various clinical and histopathological parameters were evaluated and compared. There were some limitations to this study. As data related to the postoperative follow-up were not available in all patients, treatment and prognosis could not be evaluated. Although this study can be considered to contribute to the literature, there remains a need for further retrospective and prospective randomized studies of more extensive series to evaluate the relationships of the prognosis and treatment of IPC cases with other relevant variables.

\section{Conclusion}

The results of this study demonstrated a $13.3 \%$ incidence of IPC in TUR-P. Patient age and PSA level were determined to be factors affecting IPC incidence, but no statistically significant relationship was determined with the resected specimen weight. Compared to other age groups and PSA level groups, IPC incidence was higher in patients aged $\geq 60$ years and/or with PSA level $\geq 4 \mathrm{ng}$ / 
$\mathrm{mL}$. Although no significant relationship was determined between age and T1 stages, the PSA level, Gleason GG, LVI and PNI status were determined to be statistically significantly different according to T1a and T1b stages. Compared to T1b stage, the specimen weight was greater at T1a stage, and when the cut-off value of $10 \mathrm{~g}$ was used, T1a stage was determined at a higher rate in specimens weighing $>10 \mathrm{~g}$.

According to the current study results, to be able to avoid missing IPC in patients applied with TUR-P because of BPH, especially in those aged $\geq 60$ years and/ or PSA level $\geq 4 \mathrm{ng} / \mathrm{mL}$, it can be recommended that sufficient material is sampled and carefully evaluated, and when necessary, all the resected specimen should be examined. Moreover, although no significant relationship was determined between specimen weight and IPC incidence, as there was found to be a significant difference between $\mathrm{T} 1$ stages, it can be thought that the amount of resected specimen evaluated could change the substage of the tumor. Therefore, we recommend that further studies are conducted of more extensive case series including the data of patient follow-up, treatment and prognosis to be able to reach more definitive results.

\section{Abbreviations}

PSA: Prostate-specific antigen; TUR-P: Transurethral resection of the prostate; BPH: Benign prostatic hyperplasia; IPC: Incidental prostate cancer; GG: Gleason grade group; PNI: Perineural invasion; LVI: Lymphovascular invasion; SD: Standard deviation; Cl: Confidence interval; OP: Open prostatectomy.

\section{Acknowledgements}

The authors thank Dr. Özaydın Boylubay for his valuable support in statistical analysis of the data.

\section{Authors' contributions}

All authors contributed to the development of this work. DN designed the study, obtained ethical approval, drafted of the manuscript, helped analyzed the data and edited of the manuscript. HTY helped designed the study, supervised, reviewed for critical content and revised the final manuscript. ŞY helped with manuscript preparation and collected the data and literature search. All authors read and approved the manuscript.

\section{Funding}

This study has received no financial support and sponsorship.

\section{Availability of data and material}

The datasets used and analyzed during the current study are available from the corresponding author on reasonable request.

\section{Declarations}

\section{Ethics approval and consent to participate}

This study was reviewed and approved by the ethics committee of University of Health Sciences, Antalya Training and Research Hospital (Approval number: 10/11, Date: 3/7/2020). Consent to participate was not applicable as this was a retrospective study. This decision to waiver was approved by the ethics committee of University of Health Sciences, Antalya Training and Research Hospital
(Approval number: 10/11, Date: 3/7/2020). The research followed the tenets of the Declaration of Helsinki.

\section{Consent for publication}

Not applicable.

\section{Competing interests}

The authors declare that they have no competing interests.

Received: 19 April 2021 Accepted: 4 August 2021

Published online: 19 August 2021

\section{References}

1. Bray F, Ferlay J, Soerjomataram I, Siegel RL, Torre LA, Jemal A (2008) Global cancer statistics 2018: GLOBOCAN estimates of incidence and mortality worldwide for 36 cancers in 185 countries. CA Cancer J Clin 68:394-424

2. Trpkov K, Thompson J, Kulaga A, Yilmaz A (2008) How much tissue sampling is required when unsuspected minimal prostate carcinoma is identified on transurethral resection? Arch Pathol Lab Med 132:1313-1316

3. Rajab R, Fisher G, Kattan MW, Foster CS, Møller H, Oliver T et al (2011) Transatlantic Prostate Group. An improved prognostic model for stage T1a and T1 b prostate cancer by assessments of cancer extent. Mod Pathol 24:58-63

4. Perera M, Lawrentschuk N, Perera N, Bolton D, Clouston D (2015) Incidental prostate cancer in transurethral resection of prostate specimens in men aged up to 65 years. Prostate Int 4(1):11-14

5. Ozbey C, Oztorun K (2019) Frequency of incidental cancer in transurethral prostate resection materials and our clinical approach to these patients; a retrospective file scan. Kafkas J Med 9:11-16

6. Otto B, Barbieri C, Lee R, Te AE, Kaplan SA, Robinson B et al (2014) Incidental prostate cancer in transurethral resection of the prostate specimens in the modern era. Adv Urol 2014:627290

7. Varghese J, Kuruvilla PM, Mehta N, Rathore RS, Babu M, Bansal D et al (2016) Incidentally detected adenocarcinoma prostate in transurethral resection of prostate specimens: a hospital based study from India. Asian Pac J Cancer Prev 17:2255-2258

8. Sakamoto H, Matsumoto K, Hayakawa N, Maeda T, Sato A, Ninomiya A et al (2014) Preoperative parameters to predict incidental (T1a and T1b) prostate cancer. Can Urol Assoc J 8:E815-E820

9. Paner GP, Srigley JR, Zhou M, Robert Allan R, Amin MB, Chang SS et al (2020) Collage of American Pathologists (CAP). Protocol for the examination of TURP and enucleation specimens from patients with carcinoma of the prostate gland. 2020 (February). Available from: www.cap.org/cancerprot ocols

10. Srigley JR, Humphrey PA, Amin MB, Chang SS, Egevad L, Epstein Jl et al (2009) Members of the Cancer Committee, College of American Pathologists. Protocol for the examination of specimens from patients with carcinoma of the prostate gland. Arch Pathol Lab Med 133:1568-1576

11. Epstein Jl, Egevad L, Amin MB, Delahunt B, Srigley JR, Humphrey PA (2016) Grading Committee. The 2014 international society of urological pathology (ISUP) consensus conference on Gleason grading of prostatic carcinoma: definition of grading patterns and proposal for a new grading system. Am J Surg Pathol 40:244-252

12. Humphrey PA, Moch H, Cubilla AL, Ulbright TM, Reuter VE (2016) The 2016 WHO classification of tumours of the urinary system and male genital organs — part B: prostate and bladder tumours. Eur Urol 70:106-119

13. Lee DH, Chung DY, Lee KS, Kim IK, Rha KH, Choi YD et al (2014) Clinical experiences of incidental prostate cancer after transurethral resection of prostate (TURP) according to initial treatment: a study of a Korean high volume center. Yonsei Med J 55:78-83

14. Sayar HC, Ekmekci S, Cakmak O, Kucuk U (2020) Incidental prostate adenocarcinoma in prostate transurethral resections: our eight year experience. $J$ Urol Surg 7:88-91

15. Nafie S, Dormer J, Khan MA (2017) The significance of histological analysis following laser transurethral resection of the prostate. Int Urol Nephrol 49:1343-1346 
16. Argyropoulos A, Doumas K, Farmakis A, Aristas O, Kontogeorgos G, Lykourinas $M(2005)$ Characteristics of patients with stage $T 1 \mathrm{~b}$ incidental prostate cancer. Scand J Urol Nephrol 39:289-293

17. Morita M, Matsuura T (2012) An advanced but traditional technique of transurethral resection of the prostate in order not to overlook stage T1 prostate cancer. Curr Urol 6:21-26

18. Masue N, Deguchi T, Nakano M, Ehara H, Uno H, Takahashi Y (2005) Retrospective study of 101 cases with incidental prostate cancer stages T1a and T1b. Int J Urol 12:1045-1049

19. Di Silverio F, Gentile V, De Matteis A, Mariotti G, Giuseppe V, Luigi PA et al (2003) Distribution of inflammation, pre-malignant lesions, incidental carcinoma in histologically confirmed benign prostatic hyperplasia: a retrospective analysis. Eur Urol 43:164-175
20. Cheng L, Jones TD, Lin H, Eble JN, Zeng G, Carr MD et al (2005) Lymphovascular invasion is an independent prognostic factor in prostatic adenocarcinoma. J Urol 174:2181-2185

21. Abedi AR, Ghiasy S, Fallah-Karkan M, Rahavian A, Allameh F (2020) The management of patients diagnosed with incidental prostate cancer: narrative review. Res Rep Urol 12:105-109

\section{Publisher's Note}

Springer Nature remains neutral with regard to jurisdictional claims in published maps and institutional affiliations.

\section{Submit your manuscript to a SpringerOpen ${ }^{\circ}$ journal and benefit from:}

- Convenient online submission

- Rigorous peer review

- Open access: articles freely available online

- High visibility within the field

- Retaining the copyright to your article

Submit your next manuscript at $\boldsymbol{\nabla}$ springeropen.com 